\title{
Faktor-Faktor yang Mempengaruhi Integrasi Daya Tarik Wisata (DTW) di Kawasan Wisata Bulak Surabaya
}

\author{
Faricha Astri Ananda dan Arwi Yudhi Koswara \\ Perencanaan Wilayah dan Kota, Fakultas Arsitektur Desain dan Perencanaan, \\ Institut Teknologi Sepuluh Nopember (ITS) \\ e-mail: arwi_yudhi@urplan.its.ac.id
}

\begin{abstract}
Abstrak-Kota Surabaya memiliki kawasan strategis yang berpotensi dikembangkan untuk mendukung eksistensi pengembangan wilayah kota Surabaya di masa mendatang, salah satunya adalah kawasan kota tepi pantai yang berada di Unit Pengembangan III Tambak Wedi yaitu Kecamatan Bulak. Kawasan ini memiliki beberapa Daya Tarik Wisata (DTW) dengan kunjungan wisata yang cukup besar dan dapat dikembangkan secara optimal dengan pengembangan pariwisata alam dan buatan serta permukiman nelayan. Namun wisata dan aktifitas masing-masing DTW di kawasan Bulak ini masih terpisah-pisah. Agar pengembangan kawasan wisata lebih maksimal dan merata kunjungannya, pariwisata pesisir Bulak perlu diintegrasikan keberadaan potensi DTW yang ada dalam satu kawasan wisata. Penelitian ini dilakukan untuk mengetahui faktor-faktor yang sesuai dalam mengembangkan pariwisata dengan mengintegrasikan DTW di kawasan wisata Bulak Surabaya. Metode yang digunakan adalah analisis deskriptif untuk mendapatkan karakteristik integrasi kawasan kemudian analisis delphi untuk menentukan faktor-faktor yang mempengaruhi integrasi DTW. Hasil arahan dari penelitian ini adalah faktor-faktor yang mempengaruhi integrasi daya tarik wisata di kawasan wisata Bulak Surabaya.
\end{abstract}

Kata Kunci-Faktor-faktor, Integrasi Kawasan, Pengembangan Wisata Bulak.

\section{PENDAHULUAN}

$\mathrm{P}$ ARIWISATA saat ini merupakan salah satu dari beberapa sektor yang diharapkan mampu memberikan pemasukan dan perkembangan di Indonesia. Surabaya sebagai Ibukota Jawa Timur yang merupakan salah satu propinsi yang pariwisatanya sangat potensial jika dikelola dan dikembangkan dengan baik. Sesuai dengan tujuan utama pengembangan pariwisata Kota Surabaya yaitu untuk mendukung Kota Surabaya sebagai pusat pelayanan nasional dan internasional melalui konsep city tourism[1]. Surabaya memiliki daerah tujuan wisata yang menawarkan berbagai macam jenis wisata seperti wisata alam, wisata pantai, wisata religi, wisata kuliner, wisata belanja, wisata budaya hingga wisata buatan.

Pada tahun 2016 lalu, Kota Surabaya sempat meraih terbaik kedua Indeks Pariwisata Indonesia (IPI) yang digelar oleh Kementerian Pariwisata. Hal ini membuktikan bahwa Surabaya memiliki tingkat daya saing pariwisata yang tinggi diantara kota-kota lainnya.

Surabaya memiliki kawasan strategis yang berpotensi dikembangkan secara berkelanjutan untuk mendukung eksistensi pengembangan wilayah kota di masa mendatang, salah satunya Kawasan Kota Tepi Pantai (Waterfront City) yang berada di Unit Pengembangan III Tambak Wedi di Kecamatan Bulak. Kawasan ini memiliki fungsi kegiatan utama wisata bahari/laut dengan pengembangan pariwisata alam dan buatan serta permukiman nelayan [2]

Taman Hiburan Pantai Kenjeran (THP Kenjeran) yang terletak di pesisir Kecamatan Bulak, secara konsisten dari tahun ke tahun mendapat kunjungan terbesar ketiga setelah Kebun Binatang Surabaya dan Wisata Religi Ampel [3]. Di kawasan ini terdapat sejumlah destinasi wisata alam dan buatan yang menarik dan masih tergolong daya tarik wisata baru, diantaranya Jembatan Surabaya, Sentra Ikan Bulak, Taman Bulak dan Taman Suroboyo. Dibalik sejumlah potensi pariwisata yang ada, kawasan ini juga terdapat sejumlah kampung nelayan atau disebut juga kampung warna-warni yang juga merupakan destinasi wisata baru.

Pemerintah juga melakukan upaya pengembangan wisata dengan cara menjadikan Kampung Nelayan sebagai kampung unggulan Kota Surabaya dalam field visit Prepcom III UN Habitat 2016, disana para peserta yang terdiri dari peserta domestik maupun mancanegara membeli produk nelayan Kenjeran seperti ikan dan krupuk. Selain itu pemerintah juga telah menyiapkan Sentra Ikan Bulak (SIB) di pantai Kenjeran menjadi salah satu destinasi wisata yang dikenal dunia internasional.

Namun sejak dibangunnya tahun 2012 hingga sekarang, SIB masih belum terlihat adanya perkembangan yang signifikan. Masih terlihat banyak stan yang dibiarkan terbengkalai dan kosong. Sebagian pedagang memilih berjualan di sepanjang jalan yang menghubungkan SIB dengan Taman Hiburan Pantai (THP) Kenjeran. Terdapat 212 kios yang ada di Sentra ikan Bulak ini, namun yang ditempati hanya 20 persennya saja. SIB ini merupakan solusi dari Pemerintah Kota Surabaya dalam menyelesaikan permasalahan yang terjadi di kawasan Kecamatan Bulak dengan tujuan agar dapat mengangkat perekonomian warga setempat [4]. Tidak hanya hasil olahan ikan, namun juga berbagai souvenir seperti kerajinan kerang dan oleh-oleh tersedia di Sentra Ikan Bulak.

Ada pula wisata baru yang diharapkan menjadi andalan Kota Surabaya yaitu Jembatan Surabaya yang terletak di area Pantai Kenjeran Lama Surabaya yang baru diresmikan pada 2016 lalu. Atraksi unik dari jembatan ini adalah terdapat air mancur menari dengan nyala lampu yang diikuti lagu-lagu khas Surabaya. Kunjungan wisata di jembatan ini sempat mencapai 13.300 orang pada libur lebaran 2016 lalu dan meningkat pada awal tahun 2017 mencapai 83.719 pengunjung (UPTD Kenjeran, 2017) Hingga saat ini antusias wisatawan untuk kunjungan di Jembatan Suroboyo masih tetap ramai, terutama pada malam minggu.

Dengan berbagai potensi yang ada di kawasan Bulak masih belum adanya upaya pemerintah terkait pengintegrasian kawasan ini sehingga perlu dilakukan upaya pemerataan 
kunjungan wisata upaya agar tidak terjadi ketimpangan antara area wisata pantai dan area permukiman nelayan [5]. Integrasi DTW (Daya Tarik Wisata) di Kecamatan Bulak dapat dilakukan dengan adanya dukungan letak geografis yang berdekatan antar DTW serta kemudahan dalam aksesibilitasnya. Pengembangan wisata di perkotaan dengan segala potensi yang ada dapat lebih maksimal dikembangkan dengan integrasi dalam konsep totalitas produk wisata yang saling terkait dengan yang lainnya [6]. Sehingga dengan adanya integrasi antar DTW akan saling menunjang satu dengan lainnya. Untuk itu dilakukan penelitian untuk mengidentifikasi faktor yang berpengaruh terhadap integrasi DTW di kawasan pariwisata Bulak dalam upaya pengembangan pariwisata supaya dapat berkembang secara optimal.

\section{METODE PENELITIAN}

\section{A. Jenis dan Pendekatan Penelitian}

Jenis penilitian yang digunakan pada penelitian ini adalah penelitian deskriptif kualitatif. dengan pendekatan yang digunakan adalah pendekatan rasionalistik. Penelitian rasionalistik merupakan pendekatan yang bersumber dari teori dan kebenaran empirik.

\section{B. Variabel Penelitian}

Sebelum melakukan proses analisis dalam identifikasi faktor-faktor integrasi kawasan Bulak, terlebih dahulu dilakukan proses kajian pustaka dari utama [6]-[15]. Variabel penelitian yang digunakan untuk mengidentifikasi faktorfaktor yang mempengaruhi integrasi DTW kawasan wisata Bulak dapat dilihat pada Tabel 1.

Tabel 1.

Indikator dan Variabel Penelitian

\begin{tabular}{ll}
\hline \multicolumn{1}{c}{ Indikator } & \multicolumn{1}{c}{ Variabel } \\
\hline DTW & Kedekatan antar DTW \\
& Atraksi daya tarik wisata \\
& Diferensiasi atraksi DTW \\
\hline Aksesibilitas & Jaringan jalan penghubung \\
& Moda transportasi penghubung \\
& Jalur wisata \\
\hline Fasilitas & Fasilitas pendukung wisata \\
& Ketersediaan tempat parkir terpadu \\
& Ketersediaan pusat layanan informasi \\
& Ketersediaan toko souvenir/oleh-oleh \\
& Ketersediaan penginapan \\
& Ketersediaan tempat makan terpadu \\
\hline Pengelolaan & Kelembagaan pemerintah/pengelola/investor \\
& Keterlibatan masyarakat lokal \\
& Kebijakan pengembangan wisata \\
& Promosi dan informasi wisata \\
\hline \hline
\end{tabular}

\section{Metode Pengumpulan Data}

Dalam penelitian ini menggunakan dua metode pengumpulan data yang digunakan, yaitu survei data primer dan survei data sekunder. Pengambilan sampel dalam penelitian ini menggunakan teknik purposive sampling sehingga dalam penarikan sampel menggunakan stakeholder analysis. Analisis stakeholder dalam penelitian ini merupakan para stakeholder yang mewakili pemerintah, praktisi serta stakeholder lainnya dalam penentuan pihakpihak yang berkompeten dan terlibat dalam pengelolaan, pembangunan dan pengembangan kawasan wisata Bulak.

Kriteria responden yang digunakan antara lain:

1. Responden memahami kondisi wilayah penelitian.

2. Responden memiliki pengaruh dalam mengambil keputusan terkait pengembangan kawasan penelitian.
3. Responden memiliki kepentingan dalam perumusan pengembangan kawasan penelitian.

Tabel 2.

Responden Penelitian

\begin{tabular}{|c|c|}
\hline Stakeholder & Alasan \\
\hline $\begin{array}{l}\text { Badan Perencanaan } \\
\text { Pembangunan Kota } \\
\text { Surabaya }\end{array}$ & $\begin{array}{l}\text { Pihak yang terlibat dalam perumusan } \\
\text { pembangunan kawasan wisata di wilayah } \\
\text { kota. }\end{array}$ \\
\hline Kecamatan Bulak & $\begin{array}{l}\text { Merupakan Kecamatan kawasan penelitian } \\
\text { dengan wilayahnya yang termasuk dalam } \\
\text { pengembangan pariwisata. }\end{array}$ \\
\hline UPTD Kenjeran & $\begin{array}{l}\text { Dibawahi Dinas Kebudayaan dan Pariwisata } \\
\text { Surabaya yang berperan dalam pengelolaaan } \\
\text { THP Kenjeran. }\end{array}$ \\
\hline $\begin{array}{l}\text { Pengelola } \\
\text { (Sentra Ikan Bulak) }\end{array}$ & $\begin{array}{l}\text { Pihak yang secara langsung mengelola DTW } \\
\text { sehingga sangat memahami potensi dan } \\
\text { permasalahan di tempat tersebut. }\end{array}$ \\
\hline $\begin{array}{l}\text { Ketua RW/Ketua } \\
\text { Kelompok Masyarakat } \\
\text { (permukiman nelayan) }\end{array}$ & $\begin{array}{l}\text { Pihak yang terdampak langsung atas } \\
\text { intervensi pengembangan serta sebagai } \\
\text { penyalur aspirasi warga di kawasan } \\
\text { penelitian. }\end{array}$ \\
\hline
\end{tabular}

\section{Metode Analisis Data}

Metode analisis data yang digunakan dalam penelitian ini sasaran pertama yaitu mengidentifikasi karakteristik integrasi pada kawasan wisata Bulak dengan Analisis Deskriptif Kualitatif yang didapatkan dari hasil survey primer maupun sekunder. Kemudian sasaran selanjutnya mengidentifikasi faktor-faktor yang mempengaruhi integrasi DTW kawasan menggunakan Analisis Delphi. Teknik Analisis Delphi melibatkan stakeholder sebagai pakar yang memiliki pengaruh sehingga didapatkan konsensus kesepakatan terhadap tujuan dari sasaran tersebut. Berikut adalah tahapan analisis delphi yang digunakan dalam penelitian.

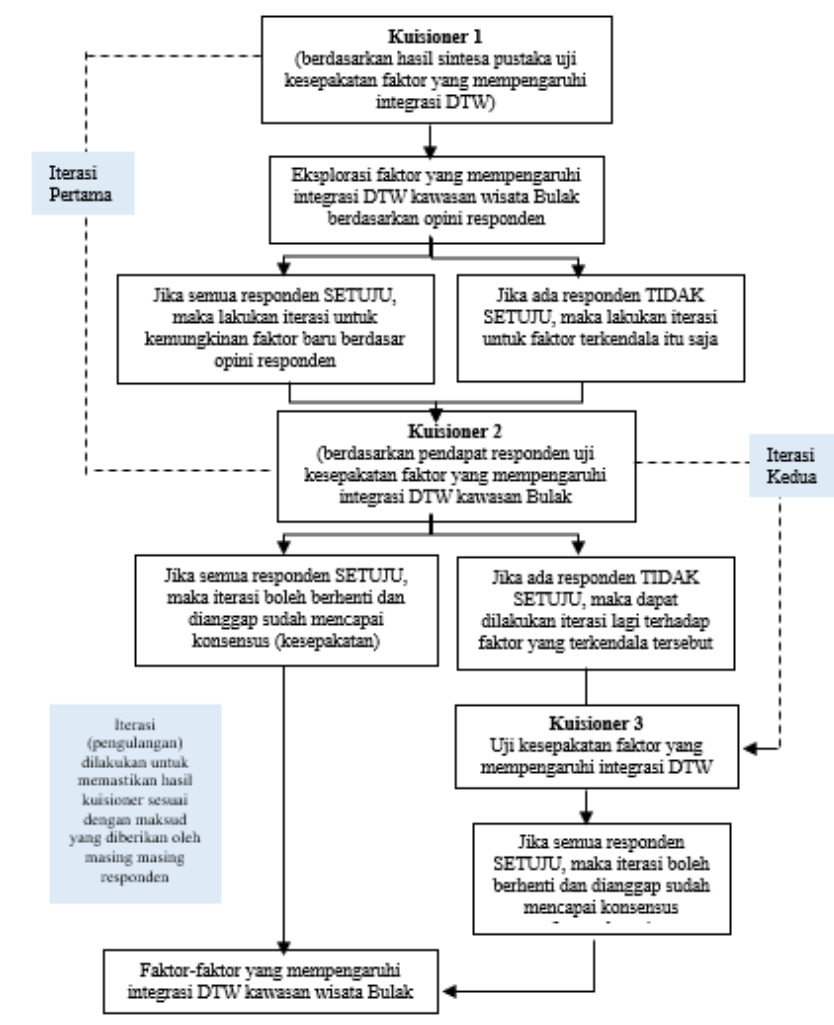

Gambar 1. Tahapan Proses Analisis Delphi. 


\section{HASIL DAN PEMBAHASAN}

A. Gambaran Umum Wilayah

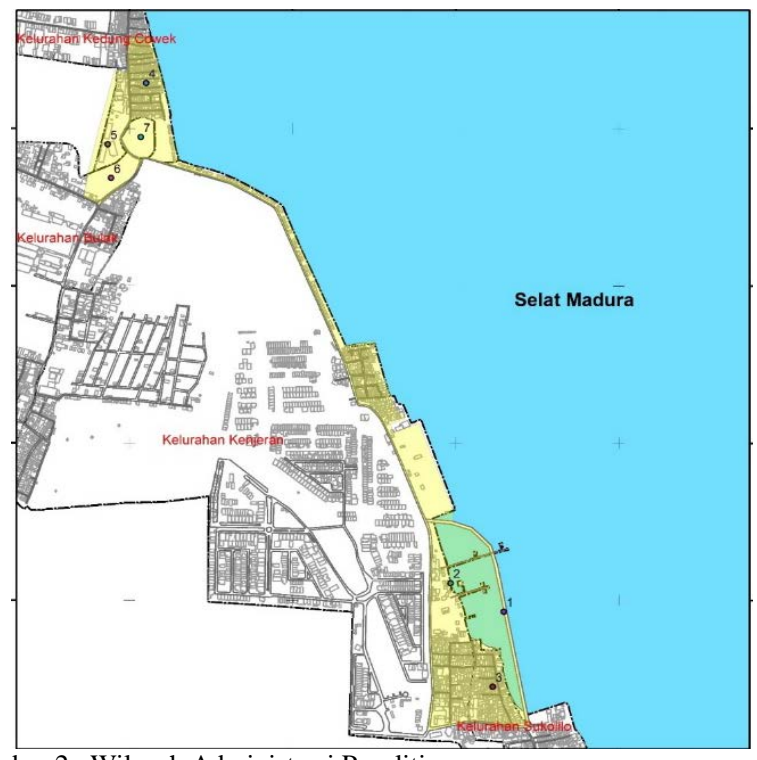

Gambar 2. Wilayah Administrasi Penelitian

Secara geografis, wilayah penelitian terletak di timur laut Surabaya dan berbatasan langsung dengan selat Madura. Kecamatan Bulak termasuk wilayah geografis Kota Surabaya yang merupakan bagian dari wilayah Surabaya Utara. Kecamatan Bulak berjarak dari kelurahan terjauh adalah 3 Km, jarak dari Pusat Pemerintahan Kota sejauh 0,7 Km dan jarak dari Pusat Pemerintahan Propinsi 7,5 Km. Luas wilayah seluruh Kecamatan Bulak $\pm 6,72 \mathrm{~km}$ terbagi menjadi 4 kelurahan antara lain Kelurahan Sukolilo Baru, Kelurahan Bulak, Kelurahan Kedung Cowek, Kelurahan Kenjeran.

Sebagian besar penduduk kecamatan Bulak bermata pencaharian sebagai pegawai swasta, nelayan dan wiraswasta Tingginya jumlah penduduk yang bermata pencaharian nelayan dan wiraswasta membuat perekonomian masyarakat sangat didominasi dari hasil perikanan dan pariwisata.

Kecamatan Bulak memiliki potensi daya tarik wisata yang beragam karena letaknya di pesisir pantai timur Surabaya. Daya tarik wisata yang cukup terkenal di Surabaya salah satunya wisata bahari satu-satunya di Surabaya yaitu pantai Kenjeran yang termasuk dalam area Kenjeran Lama. Selain jenis potensi wisata alam, ada pula potensi wisata buatan yang masih tergolong baru seperti Jembatan Suroboyo dengan atraksi mancur menari yang terletak masih dalam satu lokasi di THP (Taman Hiburan Pantai) Kenjeran, Sentra Ikan Bulak yang tergolong pasar khusus hasil tangkapan laut dan wisata kuliner. Ada pula kampung nelayan kumuh yang telah diubah menjadi kampung warna-warni yang indah. Sehingga dengan banyaknya potensi daya tarik wisata yang ada di kecamatan Bulak, diharapkan dapat meningkatkan perekonomian masyarakat setempat apabila dikembangkan dengan baik.

\section{B. Identifikasi Karakteristik Integrasi DTW}

\section{Kedekatan Jarak Antar DTW}

Taman Hiburan Pantai (THP) Kenjeran yang memiliki satu lokasi dengan Jembatan Suroboyo hanya berjarak sekitar 1,5 km dengan lokasi Sentra Ikan bulak yang berdekatan dengan kampung nelayan cumpat dan Taman Suroboyo. Jarak kedua wilayah tersebut hanya memakan waktu \pm 2 menit jika menggunakan sepeda motor.

\section{Jumlah Atraksi DTW}

Kawasan wisata Bulak terdapat 5 DTW. Atraksi wisata ini digolongkan dalam 2 kelompok, yakni atraksi wisata buatan dan atraksi wisata alam, antara lain THP Kenjeran, Jembatan Suroboyo, Sentra Ikan Bulak, Taman Suroboyo dan Kampung Nelayan Bulak Cumpat. Adapun jenis kegiatan yang termasuk kedalamnya adalah kegiatan berperahu, aktifitas di taman, melihat kehidupan para nelayan, berbelanja hasil olahan laut maupun souvenir, serta kegiatan dokumentasi pada spot-spot yang telah disediakan secara sengaja (pemandangan buatan; atraksi, fasilitas wisata) dan tidak sengaja (pemandangan alam).

\section{Diferensiasi Atraksi DTW}

Atraksi wisata di kawasan ini berupa atraksi buatan dan fisik diantaranya Taman Hiburan Pantai Kenjeran (THP), Jembatan Suroboyo dengan atraksi tambahan air mancur menari, Taman Suroboyo, Taman Bulak serta Sentra Ikan Bulak sebagai atraksi DTW belanja. Sedangkan, atraksi alami yaitu Pantai Kenjeran serta kampung pesisir bulak yang dicat warna-warni dan mengutamakan atraksi dan aktivitas pesisir di kampung wisatanya.

\section{Jaringan Jalan Penghubung}

Kondisi jalan yang menghubungkan antar DTW di Kecamatan Bulak sudah sangat baik dan nyaman dengan kondisi sudah beraspal tanpa adanya jalan berlubang maupun bergelombang.

\section{Moda Transportasi Penghubung}

Belum ada transportasi umum maupun khusus yang menghubungkan antar DTW (THP Kenjeran sampai Sentra Ikan Bulak, begitu pula sebaliknya). Selama ini wisatawan menggunakan kendaraan pribadi untuk mencapai masingmasing DTW di kawasan Bulak.

\section{Rute Perjalanan Antar DTW}

Pada kawasan wisata Bulak ini masih belum terdapat adanya jalur wisata atau rute perjalanan wisata. Untuk kunjungan wisata biasanya wisatawan secara acak langsung mengunjungi objek mana yang ingin mereka datangi, sehingga tidak semua DTW merata dikunjungi

\section{Ketersediaan Fasilitas Pendukung Wisata}

Pada kawasan wisata ini sudah dilengkapi oleh penandaan/signage sehingga mempermudah wisatawan untuk mengetahui direksi kawasan wisata. Adapun jenis penandaan yang tersedia adalah berupa penandaan arah dan penandaan berupa informasi nama wisata. Serta belum terdapatnya jaringan perbankan di kawasan ini

\section{Ketersediaan Pusat Layanan Informasi}

Karena belum terintegrasinya kawasan wisata Bulak ini, masih belum terdapat adanya pusat layanan informasi atau Tourist Information Center (TIC) mengenai pariwisata di Kecamatan Bulak yang berada di kawasan wisata ini

\section{Ketersediaan tempat parkir terpadu}

Tiap DTW telah memiliki tempat parkirnya masingmasing seperti Sentra Ikan Bulak, THP Kenjeran, Taman Suroboyo. Namun tempat parkir ini masih sendiri-sendiri belum adanya tempat parkir yang terpadu. Karena belum terintegrasinya DTW di kawasan ini sehingga wisatawan datang sendiri langsung ke DTW yang mereka inginkan.

\section{Ketersediaan toko souvenir/ oleh-oleh}

Fasilitas layanan tambahan semacam toko souvenir untuk membeli oleh-oleh sudah terdapat di Sentra Ikan Bulak (SIB). Namun SIB ini masih sepi kunjungannya dilihat dari lapak penjual yang masih sepi pula. Ketersediaan toko souvenir dan oleh- oleh juga terdapat di THP Kenjeran. Namun belum ada nya tempat perbelanjaan oleh-oleh terpusat. 


\section{Ketersediaan food services/tempat makan}

Ketersediaan tempat makan sudah terakomodasi di kawasan THP Kenjeran dan kawasan Sentra Ikan Bulak masing-masing telah memiliki tempat makan untuk berwisata kuliner. Masih sama seperti fasilitas lainnya, ketersediaan tempat makan ini masih berjalan sendiri di DTW nya. Belum adanya tempat makan terpadu yang terintegrasi dengan DTW lainnya.

\section{Kelembagaan pemerintah/ pengelola/ investor}

Pengelolaan daya tarik wisata di kawasan wisata Bulak ini dikelola oleh Pemerintah Kota Surabaya. Sentra Ikan Bulak dibawahi oleh Dinas Ketahanan Pangan dan Pertanian namun tetap berkoordinasi dengan dinas-dinas lainnya. Upaya yang dilakukan dalam pengembangan kawasan wisata Bulak berupa kegiatan kolaborasi yang melibatkan berbagai aktor dalam pelaksanaannya.

\section{Keterlibatan masyarakat lokal}

Partisipasi masyarakat di kawasan pariwisata Bulak masih tergolong rendah, terutama pada daerah kampung nelayan. Kurangnya kesadaran masyarakat kampung nelayan dan sekitarnya akan potensi kawasannya sebagai tujuan wisata dilihat dari lingkungannya yang masih banyak sampah, menjemur ikan sembarangan dan membuang sisa hasil olahan laut sembarangan. Namun pelan-pelan masyarakat kampung nelayan mulai berangsur menyadari pentingnya menjaga lingkungan bersih dan berbudaya.

\section{Kebijakan pengembangan wisata}

Penetapan kawasan pariwisata dan kampung nelayan Bulak telah dikembangkan dengan dukungan kebijakan dari ditetapkannya kawasan ini sebagai kawasan pariwisata melalui Rencana Tata Ruang Wilayah (RTRW) Kota Surabaya dan RZWP. Hal ini juga telah di rencanakan dalam Rencana Induk Pengembangan Pariwisata Daerah (RIPPDA) Surabaya 2017.

\section{Promosi dan informasi wisata}

Terdapat berbagai cara untuk melakukan pemasaran kawasan wisata, salah satu metode yang digunakan oleh karang taruna Kecamatan Bulak adalah melalui media sosial seperti Facebook, Twitter, dan Instagram. Hal ini disebabkan kecenderungan pasar yang saat ini mayoritas merupakan pengguna media sosial. Sehingga, diharapkan wisata di kawasan Bulak ini dapat lebih dikenal dan menarik masyarakat untuk berkunjung serta mempermudah masyarakat untuk mengetahui lokasi, atraksi, dan sarana prasarana lain yang ditawarkan oleh pemerintah.

\section{Keterlibatan pihak swasta}

Sejauh ini masih belum ada keterlibatan pihak swasta dalam pengembangan wisata di kawasan wisata Bulak. Pemerintah dan masyarakat lokal yang berperan aktif dalam pengelolaan kawasan ini namun belum ada keterlibatan dari pihak swasta dalam pengelolaan maupun promosi.

\section{Faktor-Faktor yang Berpengaruh dalam Integrasi DTW Pariwisata Bulak}

Dalam menentukan faktor-faktor yang mempengaruhi integrasi daya tarik wisata di kawasan pariwisata Bulak dilakukan teknik Analisa Delphi yang bertujuan mendapatkan konsensus (kesepakatan pendapat) berdasarkan opini pakar/stakeholder yang merupakan responden penelitian yang telah ditentukan pada Analisis Stakeholder sebelumnya. Pada tahap ini responden menyatakan kesetujuan dan ketidaksetujuan terhadap variabel-variabel yang ditampilkan dalam kuisioner Delphi tahap 1. Berikut merupakan hasil eksplorasi pendapat dari para responden mengenai faktor yang mempengaruhi integrasi pariwisata Bulak.

Tabel 5.

Hasil Eksplorasi Delphi Tahap 1

\begin{tabular}{|c|c|c|c|c|c|}
\hline Faktor-faktor & 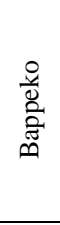 & 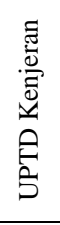 & 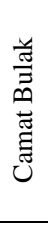 & 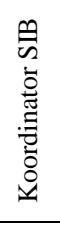 & 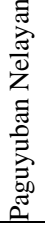 \\
\hline Kedekatan antar DTW & S & $\mathrm{S}$ & $\mathrm{S}$ & $\mathrm{S}$ & $\mathrm{S}$ \\
\hline Jumlah atraksi DTW & TS & $\mathrm{S}$ & $\mathrm{S}$ & $\mathrm{S}$ & $\mathrm{S}$ \\
\hline Diferensiasi atraksi DTW & $\mathrm{S}$ & $\mathrm{S}$ & $\mathrm{S}$ & $\mathrm{S}$ & $\mathrm{S}$ \\
\hline Jaringan jalan penghubung & $\mathrm{S}$ & $\mathrm{S}$ & $\mathrm{S}$ & $\mathrm{S}$ & $\mathrm{S}$ \\
\hline Moda transportasi penguhung & $\mathrm{S}$ & $\mathrm{S}$ & $\mathrm{S}$ & $\mathrm{S}$ & $\mathrm{S}$ \\
\hline Rute perjalanan antar DTW & $\mathrm{S}$ & S & $\mathrm{S}$ & $\mathrm{S}$ & $\mathrm{S}$ \\
\hline Ketersediaan fasilitas pendukung & $\mathrm{S}$ & $\mathrm{S}$ & $\mathrm{S}$ & $\mathrm{S}$ & $\mathrm{S}$ \\
\hline Ketersediaan tempat parkir terpadu & $\mathrm{S}$ & $\mathrm{S}$ & $\mathrm{S}$ & $\mathrm{S}$ & $\mathrm{S}$ \\
\hline Ketersediaan pusat layanan informasi & $\mathrm{S}$ & $\mathrm{S}$ & $\mathrm{S}$ & $\mathrm{S}$ & $\mathrm{S}$ \\
\hline Ketersediaan toko souvenir/oleh-oleh & $\mathrm{S}$ & $\mathrm{S}$ & $\mathrm{S}$ & $\mathrm{S}$ & $\mathrm{S}$ \\
\hline Ketersediaan penginapan & TS & TS & $\mathrm{S}$ & TS & $\mathrm{S}$ \\
\hline Ketersediaan tempat makan terpadu & $\mathrm{S}$ & $\mathrm{S}$ & $\mathrm{S}$ & $\mathrm{S}$ & $\mathrm{S}$ \\
\hline $\begin{array}{l}\text { Kelembagaan pemerintah/ pengelola/ } \\
\text { investor }\end{array}$ & $\mathrm{S}$ & $\mathrm{S}$ & $\mathrm{S}$ & $\mathrm{S}$ & $\mathrm{s}$ \\
\hline Keterlibatan masyarakat lokal & TS & S & $\mathrm{S}$ & $\mathrm{S}$ & $\mathrm{S}$ \\
\hline Kebijakan pengembangan wisata & $\mathrm{S}$ & $\mathrm{S}$ & $\mathrm{S}$ & $\mathrm{S}$ & $\mathrm{S}$ \\
\hline Promosi dan informasi wisata & $\mathrm{S}$ & $\mathrm{S}$ & $\mathrm{S}$ & $\mathrm{S}$ & $\mathrm{S}$ \\
\hline
\end{tabular}

Selain 16 faktor yang mempengaruhi integrasi diatas, responden penelitian juga menambahkan tambahan faktor baru yang merupakan rekomendasi faktor yang mempengaruhi integrasi DTW kawasan wisata Bulak. Stakeholder dari Bappeko menambahkan faktor "adanya keterlibatan pihak swasta”. Responden menambahkan faktor ini karena jika pihak swasta bersedia dilibatkan akan semakin memajukan pariwisata di kawasan bulak ini. Adanya peran swasta dalam integrasi DTW di kawasan Kecamatan Bulak untuk menambah sarana promosi ke pihak luar supaya datang berwisata ke DTW di kecamatan Bulak. Selama ini promosi yang dilakukan sudah cukup intens dilakukan pemerintah kota Surabaya. namun, kedepannya diperlukan kerjasama event dengan pihak swasta yang bertempat di kawasan ini agar lebih diketahui keberadaannya oleh masyarakat.

Setelah dilakukan eksplorasi Delphi tahap I, dari hasil tersebut masih terdapat variabel yang masih belum konsensus atau kesepakatan masih belum tercapai antar responden. Sehingga perlu dilakukan eksplorasi Delphi tahap II (iterasi I) untuk beberapa variabel yang belum mencapai kesepakatan seluruh responden. Berikut ini merupakan hasil kompilasi analisis Delphi tahap II.

Tabel 6

Hasil Eksplorasi Delphi Tahap 2

\begin{tabular}{|c|c|c|c|c|c|}
\hline Faktor-faktor & 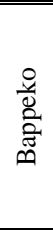 & 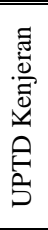 & 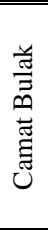 & 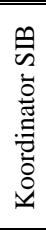 & 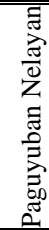 \\
\hline Kedekatan antar DTW & $\mathrm{S}$ & $\mathrm{S}$ & $\mathrm{S}$ & $\mathrm{S}$ & $\mathrm{S}$ \\
\hline Jumlah atraksi DTW & TS & $\mathrm{S}$ & $\mathrm{S}$ & $\mathrm{S}$ & $\mathrm{S}$ \\
\hline Diferensiasi atraksi DTW & S & $\mathrm{S}$ & $\mathrm{S}$ & $\mathrm{S}$ & $\mathrm{S}$ \\
\hline Jaringan jalan penghubung & S & $\mathrm{S}$ & $\mathrm{S}$ & $\mathrm{S}$ & $\mathrm{S}$ \\
\hline Moda transportasi penguhung & S & $\mathrm{S}$ & $\mathrm{S}$ & $\mathrm{S}$ & $\mathrm{S}$ \\
\hline Rute perjalanan antar DTW & S & $\mathrm{S}$ & $\mathrm{S}$ & $\mathrm{S}$ & $\mathrm{S}$ \\
\hline Ketersediaan fasilitas pendukung & S & $\mathrm{S}$ & $\mathrm{S}$ & $\mathrm{S}$ & $\mathrm{S}$ \\
\hline Ketersediaan tempat parkir terpadu & S & $\mathrm{S}$ & $\mathrm{S}$ & $\mathrm{S}$ & $\mathrm{S}$ \\
\hline Ketersediaan pusat layanan informasi & S & $\mathrm{S}$ & $\mathrm{S}$ & $\mathrm{S}$ & $\mathrm{S}$ \\
\hline Ketersediaan toko souvenir/oleh-oleh & S & $\mathrm{S}$ & $\mathrm{S}$ & $\mathrm{S}$ & $\mathrm{S}$ \\
\hline
\end{tabular}




\begin{tabular}{|c|c|c|c|c|c|}
\hline Faktor-faktor & 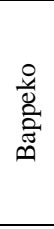 & 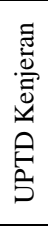 & $\begin{array}{l}\frac{y}{\widetilde{J}} \\
\vec{\Xi} \\
\stackrel{\Xi}{\Xi} \\
\underset{\Xi}{U}\end{array}$ & 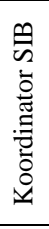 & 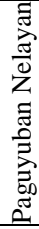 \\
\hline Ketersediaan penginapan & TS & TS & $\mathrm{S}$ & TS & $\mathrm{S}$ \\
\hline Ketersediaan tempat makan terpadu & $\mathrm{S}$ & $\mathrm{S}$ & S & S & $\mathrm{S}$ \\
\hline $\begin{array}{l}\text { Kelembagaan pemerintah/ pengelola/ } \\
\text { investor }\end{array}$ & S & $\mathrm{S}$ & S & S & $\mathrm{S}$ \\
\hline Keterlibatan masyarakat lokal & TS & $\mathrm{S}$ & S & S & S \\
\hline Kebijakan pengembangan wisata & $\mathrm{S}$ & $\mathrm{S}$ & S & S & $\mathrm{S}$ \\
\hline Promosi dan informasi wisata & S & $\mathrm{S}$ & S & $\mathrm{S}$ & $\mathrm{S}$ \\
\hline Keterlibatan pihak swasta & $\mathrm{S}$ & $\mathrm{S}$ & $\mathrm{S}$ & $\mathrm{S}$ & $\mathrm{S}$ \\
\hline
\end{tabular}

Setelah dilakukan eksplorasi delphi kedua, seluruh responden tidak setuju dengan faktor ketersedian penginapan karena sejauh ini kebanyakan pengunjung merupakan wisatawan lokal dan kalaupun dari luar kota kebanyakan menginap di tengah kota. Jarang pula ada wisatawan yang menginap di daerah Bulak meskipun telah tersedia fasilitas akomodasi. Berdasarkan fase pengembangan daya tarik wisata dari pola pembangunan daya tarik wisata di kota Surabaya, DTW di kawasan ini masih pada tahap eksplorasi dan tahap pengembangan sehingga belum pula terdapat atraksi atau sesuatu yang khas di kawasan ini yang membuat pengunjung sampai menginap. Tanpa adanya faktor ini kawasan wisata Bulak tetap dapat terintegrasi sehingga faktor ini tidak berpengaruh.

\section{KESIMPULAN}

Didapati antar DTW memiliki kedekatan dan sejumlah DTW yang beragam jenis, dengan jaringan jalan penghubung dan ketersediaan fasilitas pendukung wisata yang yang memadahi namun antar DTW masih belum terintegrasi dilihat dari belum adanya fasilitas yang terpadu, belum adanya rute perjalanan/jalur wisata, moda transportasi penghubung, serta ketersediaan Tourist Information Center (TIC) dan keterlibatan pihak swasta dalam pengelolaannya.

Berdasarkan dari keseluruhan proses analisis yang dilakukan, didapatkan faktor-faktor yang mempengaruhi integrasi di kawasan wisata Kecamatan Bulak antara lain: (1) kedekatan antar DTW, (2) jumlah atraksi DTW, (3) diferensiasi atraksi DTW, (4) ketersediaan fasilitas pendukung, (5) ketersediaan parkir terpadu, (6) ketersediaan pusat layanan informasi, (7) ketersediaan toko souvenir/oleholeh, (8) ketersedian tempat makan terpadu, (9)jaringan jalan penghubung, (10)moda transportasi penghubung, (11) rute perjalanan antar DTW, (12) kelembagaan pemerintah/ pengelola/ investor, (13) keterlibatan masyarakat lokal, (14) keterlibatan pihak swasta, (15) kebijakan pengembangan wisata, (16) promosi dan informasi wisata.

\section{UCAPAN TERIMA KASIH}

Penulis mengucapkan terima kasih kepada Bappeko Surabaya, Kecamatan Bulak, UPTD Kenjeran, Koordinator Sentra Ikan Bulak dan Paguyuban Nelayan yang telah memberikan informasi, waktu dan ilmunya sehingga penyusunan penelitian ini dapat selesai tepat waktu. Terimakasi pula kepada seluruh pihak yang membantu dalam penelitian ini Penulis menyadari bahwa penulisan dan pengerjaan penelitian ini masih jauh dari kesempurnaan, semoga dapat memberikan manfaat dan wawasan bagi berbagai pihak.

\section{DAFTAR PUSTAKA}

[1] PERDA Kota Surabaya No. 12 Th. 2014 tentang Rencana Tata Ruang Wilayah Kota Surabaya Th. 2014-2034.

[2] PERDA Kota Surabaya No. 10 Th. 2016 tentang Rencana Pembangunan Jangka Menengah Daerah Kota Surabaya Th. 20162021

[3] PERDA JATIM No. 6 Th. 2017 tentang Rencana Induk Pembangunan Kepariwisataan Provinsi Jawa Timur Th. 2017-2032.

[4] E. N. Sari and M. F. Ma'ruf, "Partisipasi pedagang dalam pengembangan Sentra Ikan Bulak (SIB) di kecamatan Bulak kota Surabaya,” Publika, vol. 5, no. 1, 2017.

[5] F. A. Hardiyanti and M. Faqih, "Konsep perancangan kampung baru nelayan Kenjeran Surabaya,” J. Sains dan Seni ITS, vol. 5, no. 2, pp. 293-298, 2016.

[6] G. B. R. Utama, "Pengembangan wisata kota sebagai pariwisata masa depan,” in Seminar Nasional SPACE\#1, 2013.

[7] S. N. Damayanti and R. Suprihardjo, "Pembentukan Cluster Objek Daya Tarik Wisata (ODTW) di Kota Yogyakarta,” J. Tek. ITS, vol. 5, no. 1, pp. C54-C58, 2016

[8] S. Fadilah and R. Suprihardjo, "Pengembangan kawasan wisata bahari kecamatan Watulimo, kabupaten Trenggalek,” J. Tek. ITS, vol. 5, no. 1, pp. C50-C53, 2016.

[9] M. Fadli, "Arahan integrasi kawasan ekowisata bahari di Pantai Bangsring dan Pulau Tabuhan, Kabupaten Banyuwangi,” Institut Teknologi Sepuluh Nopember, Surabaya, 2017.

[10] A. Khomenie and E. Umilia, "Arahan pengembangan kawasan wisata terpadu Kenjeran Surabaya,” J. Tek. ITS, vol. 2, no. 2, pp. C87-C91, 2013.

[11] S. Nordin, “Tourism clustering \&amp; Innovation,” Ostersund, Sweden, 2003.

[12] M. Oktavia, R. Suprihardjo, and E. B. Santoso, "Pengembangan kawasan pariwisata perkotaan di kota Sumenep," in Prosiding SENATEK 2015, 2015, pp. 1055-1063.

[13] A. Postma, "An approach for integrated development of quality tourism,” in ATLAS 10th Anniversary Confererence, 2002.

[14] J. J. Spillane, Ekonomi pariwisata: sejarah dan prospeknya. Yogyakarta: Kanisius, 1987.

[15] S. P. Warpani, Pariwisata dalam tata ruang wilayah. Bandung: ITB, 2007.

[16] O. A. Yoeti, Pengantar Ilmu Pariwisata. Bandung: Angkasa, 2005. 